\title{
Structural Rationality and the Property of Coherence
}

Marc-Kevin Daoust, Harvard University. mk.daoust@live.ca

Paper forthcoming in Pacific Philosophical Quarterly. DOI: 10.1111/papq.12404. Please cited the published version.

Abstract: What is structural rationality? Specifically, what is the distinctive feature of structural requirements of rationality? Some philosophers have argued, roughly, that the distinctive feature of structural requirements is coherence. But what does coherence mean, exactly? Or, at least, what do structuralists about rationality have in mind when they claim that structural rationality is coherence? This issue matters for making progress in various active debates concerning rationality. In this paper, I analyze three strategies for figuring out what coherence means in the debates on structural rationality. I argue that these strategies face problems.

Keywords: coherence, structural rationality, consistency, akrasia, instrumental rationality, nature of rationality

Linda believes that she is a bank teller and she also believes that she is not a bank teller. She displays a kind of irrationality. Specifically, she is structurally irrational. But what is structural (ir)rationality, exactly?

Some philosophers don't really tell us what 'structural rationality' means. They simply analyze a variety of putative structural requirements individually (e.g., Broome 2013). For them, whether these requirements have a common denominator, or whether there exists a method for identifying structural requirements, is an open question. So, why is Linda structurally irrational? It is because we think there is a structural requirement prohibiting believing $\mathrm{P}$ and disbelieving P simultaneously, but we don’t necessarily know why. As Broome says, 'I am sorry to say I cannot [describe a general method for identifying requirements of rationality]' (ibid., 150).

Other philosophers take a different approach. Instead of analyzing each putative structural requirement individually, they think we can work from a distinctive feature shared by all structural requirements. According to a popular suggestion, structural 
rationality is coherence. ${ }^{1}$ So, why is Linda structurally irrational? This could be because believing $\mathrm{P}$ and disbelieving $\mathrm{P}$ simultaneously is incoherent.

This paper is concerned with the claim that coherence is the distinctive feature of structural requirements of rationality. I will raise some worries about this suggestion. Although I believe that identifying a distinctive feature underlying all structural requirements is the right strategy, we still lack an account of coherence that fulfills this objective.

I can think of three strategies for figuring out what coherence means in the debates on structural rationality: ${ }^{2}$

1. We can explore the genealogy of this debate - that is, we can turn to papers in which the Why-Be-Rational? debate started. Perhaps these papers will tell us what coherence is supposed to mean in these debates.

2. We can turn to other fields that have theorized norms of coherence, such as epistemology or ethics. Perhaps the accounts of coherence found in these fields will correspond to what structuralists have in mind.

3. We can turn to regimented accounts of coherence that are tailored to unify the putative structural requirements of rationality.

However, I will argue that these strategies raise problems. We haven't found an account of coherence that unifies structural requirements of rationality, or that reflects what structuralists about rationality (i.e., people who think that there are structural requirements of rationality) have in mind.

In section 1, I present the problem more clearly. In section 2, I argue that the papers in which the Why-Be-Rational? debate originated are unclear about the nature of coherence. In section 3, I argue that it is implausible that the concept of coherence in the

1 See, e.g., Lee (2020), Mildenberger (2019), and Worsnip (2018a; 2018b; 2019). Fogal (2020) refers to structural rationality and coherence nearly interchangeably. Kolodny (2005) says that rationality is tied to coherence (although some of his remarks also suggest that first-order requirements-like, e.g., the requirement not to believe $\mathrm{P}$ and disbelieve $\mathrm{P}$ simultaneously_are not genuine requirements). Reisner (2013) equates rationality with consistency. Easwaran and Fitelson (2015) say that there are rational requirements of coherence, but that their common denominator is nondominance (more on this point in section 4.1).

2 There can be some overlap between strategies. 
Why-Be-Rational? debate means the same thing as in other fields, such as in ethics or epistemology. In section 4, I analyze two accounts of coherence that could unify structural requirements of rationality-namely, the sure-losses account of coherence and the dispositionalist account of coherence. I argue that these accounts have shortcomings when it comes to unifying the putative structural requirements. In conclusion, I briefly discuss three good avenues for future research.

\section{A Closer Look at the Problem}

In this section, I begin by briefly summarizing two debates on structural rationality (§1.1). I argue that one difficulty in these debates is that, instead of analyzing a common denominator underlying all the structural requirements, we often focus exclusively on specific putative requirements of rationality. Call this the Requirement-Based Approach (§1.2). A better way to analyze structural requirements would be to identify a distinctive feature underlying them. Call this the Property-Based Approach (§1.3).

\subsection{The Why-Be-Rational Challenge and the Elimination of Structural Requirements}

In the past 20 years, many philosophers have tried to answer the Why-Be-Rational? Challenge. ${ }^{3}$ That is, they have tried to figure out whether agents fall under an obligation to be rational, or whether agents have reasons to be rational.

Initially, the debate was focused on structural requirements of rationality. ${ }^{4}$ Let's say, provisionally, that structural requirements of rationality prohibit inconsistent combinations of beliefs or intentions, or akratic combinations of attitudes, and the like (more on this point later). By contrast, there are some putative substantive requirements of rationality. Very roughly, substantive requirements have to do with the way agents respond to the reasons they have.

Some influential objections against the normativity of structural requirements come from Kolodny. One of his objections is that being structurally rational does not matter, because agents can satisfy structural requirements while being entirely wrong or

3 See, e.g., Kolodny (2005; 2007; 2008a; 2008b), Broome (2013), Kiesewetter (2017), Wedgwood (2017), Lord (2018), Mildenberger (2018), Worsnip (2021). See Way (2010) for an overview of the debate.

4 Later, some authors like Lord (2018) and Kiesewetter (2017) argued that we have reason to comply with the requirements of substantive rationality, and that we can explain structural irrationality away in terms of a failure to comply with the substantive requirements. 
unreasonable. ${ }^{5}$ Kolodny has also objected that it is hard to see the place of structural requirements in first-personal deliberation. Structural requirements do not seem to guide us. When we deliberate, we think about our reasons for or against some attitudes, not whether we will satisfy some structural requirements of rationality. ${ }^{6}$

Still, it seems that agents who violate structural requirements fail to believe and intend what they should. In order to account for this intuition, Kolodny (2007) argues that, when agents fail to satisfy a putative structural requirement of rationality, this can be explained in terms of a more fundamental normative failure. Specifically, he argues that structurally irrational agents fail to respond correctly to their (possessed or available) reasons. Other philosophers, like Lord (2014; 2018) and Kiesewetter (2017), have made similar claims. Thus, they think that structural requirements are not normative, but that we can explain what's wrong with failing to satisfy these requirements in terms of something else. Call this the Elimination Thesis.

\subsection{The Requirement-Based Approach}

As we just saw, there are two ongoing debates concerning structural rationality: First, are structural requirements normative? Second, can we explain away structural requirements in terms of other requirements, such as requirements of reasons-responsiveness? In both debates, a recurrent problem is that we don't know how to identify the structural requirements of rationality. That is, we don't know exactly what counts as a structural requirement and what doesn't.

Take the Elimination Thesis. It roughly says that, if agents satisfy some normative requirements (such as responding correctly to the reasons they have), they automatically satisfy the structural requirements of rationality. In order to vindicate the Elimination Thesis, we need to find some sort of connection between normative requirements and structural requirements.

There are at least two ways to do this. First, we can analyze each putative structural requirement individually and try to figure out whether responding correctly to reasons one has automatically entails satisfying these putative requirements. This is a RequirementBased Approach — here we would primarily focus on requirements. Second, we could find a

5 See Kolodny (2007).

6 See Kolodny (2005) and Worsnip (2021). 
distinctive feature, or property, underlying all the putative structural requirements and argue that requirements of reason have (or entail) this property. This is a Property-Based Approach-here we would primarily focus on a property underlying putative structural requirements.

Begin with the Requirement-Based Approach. There are neat studies of putative structural requirements in Broome (2013), Kiesewetter (2017) and Lord (2018). In chapters 9 and 10 of The Normativity of Rationality, Kiesewetter discusses how reasons-responsive agents will satisfy various putative structural requirements. In chapter 2 of The Importance of Being Rational, Lord also analyzes various structural requirements and argues that reasons-responsive agents will satisfy them.

However, focusing on requirements is burdensome and gives limited results. ${ }^{7}$ Kiesewetter (2017, chaps. 9-10), for instance, spends two chapters of his book analyzing four putative structural requirements-namely:

Practical Enkrasia. Rationality requires that, if A believes that she ought to $\phi$, then A intends to $\phi$.

Doxastic Enkrasia. Rationality requires that, if A believes that she has sufficient evidence that $\mathrm{P}$, then A believes that $\mathrm{P}$.

Modus Ponens Rationality. Rationality requires that, if A believes that $\mathrm{p}$, and A believes that $\mathrm{p} \rightarrow \mathrm{q}$, then A believes that $\mathrm{q}$.

Instrumental Principle. Rationality requires that, if A intends to $\phi$, and A believes that $\psi-$ ing is a necessary means to $\phi$-ing, then $\mathrm{A}$ intends to $\psi$.

The problem is that there is a very, very long list of putative structural requirements. For instance, there are many different formulations of enkratic (or inter-level) requirements, in terms of rationality, evidence, reasons, knowledge, justification, obligation and reasons. ${ }^{8}$ Obviously, claims concerning epistemic rationality, knowledge, justification, epistemic obligations and evidence are related in some ways. However, we cannot assume that all these different formulations are equivalent. So, each one of them requires a separate analysis.

7 But of course, we can learn interesting things by studying individual putative structural requirements. See, e.g., Daoust (2019; 2020; 2021).

8 See, for example, the different formulations of enkratic principles in Horowitz (2014), Broome (2013), Feldman (2005), Lasonen-Aarnio (2015; 2020), and Titelbaum (2015). See Daoust (2019) for discussion. 
There are putative structural requirements prohibiting Moore-paradoxical combinations of beliefs or assertions. ${ }^{9}$ Some requirements prohibit the commissive form (i.e., asserting or believing that $\mathrm{P}$ while believing that $\mathrm{P}$ is false), and other requirements prohibit the omissive form (i.e., asserting or believing that $\mathrm{P}$ is the case, but refraining from believing P). ${ }^{10}$ In Bayesian epistemology, there are many putative structural requirements, including Probabilism, ${ }^{11}$ Conditionalization, ${ }^{12}$ some omniscience requirements for a priori or logical truths, ${ }^{13}$ and some Inter-Level Coherence requirements (such as Rational Reflection and Immodesty). ${ }^{14}$ In the practical realm, there are putative structural requirements governing the transitivity of preferences, ${ }^{15}$ combinations of desires and beliefs, ${ }^{16}$ combinations of goals and beliefs about possible actions, ${ }^{17}$ and so forth. Given the variety of putative structural requirements discussed in print, analyzing each individual putative structural requirement would be burdensome.

Also, note that the list of structural requirements discussed by philosophers can easily evolve over time. Take recent work on degrees of intention. Many philosophers think that agents can rationally entertain degrees of intention. Some practical scenarios that are similar in fashion to the preface paradox support such a conclusion. ${ }^{18}$ Here is one of such cases:

Tourism. Michelle is planning to visit twenty cathedrals during her trip to Europe. However, she doesn't have the money to visit all these cathedrals. In fact, she has just enough money to visit nineteen cathedrals. However, Michelle thinks that at least one of the twenty cathedrals will be closed for renovations, so she won't be able to visit it. So, even though she knows that she won't be able to visit all these cathedrals, she stills plans to visit all of them individually.

In Tourism, Michelle intends to visit Cathedral ${ }_{1}$, intends to visit Cathedral ${ }_{2}, \ldots$, and intends to visit Cathedral 20 . Yet she knows that her intentions, when closed under conjunction, will fail. That is, she knows that the conjunct (visiting Cathedral ${ }_{1}$ and Cathedral $_{2}$ and... Cathedral $_{20}$ ) will not happen. Typically, it is odd for agents to intend things that they know

9 Chislenko (2016), Feldman (2005), Huemer (2007) and Smithies (2012).

10 Smithies (2016).

11 Joyce (1998), Leitgeb and Pettigrew (2010a; 2010b), Pettigrew (2016).

12 Greaves and Wallace (2006), Meacham (2015), Schoenfield (2017).

13 Easwaran (2011), Dogramaci (2018).

14 Daoust (2021), Lewis (1971), Joyce (2009), Elga (2010; 2013), Lasonen-Aarnio (2015).

15 Davidson, McKinsey and Suppes (1955).

16 Nozick (1993, 144-6).

17 Ibid.

18 As in Holton (2008) or Golstein (2016). See Archer (2017) for critical discussion of Holton's argument. 
for sure won't happen. ${ }^{19}$ So, how can we make sense of the fact that Michelle intends to visit Cathedral ${ }_{1}$, intends to visit Cathedral $2, \ldots$, and intends to visit Cathedral ${ }_{20}$ ?

One solution is to admit that Michelle has degrees of intention to visit various cathedrals. The argument runs as follows: Typically, if A intends to $\varphi$, A (implicitly) believes that he or she will succeed in $\varphi$-ing. However, A may merely have a degree of belief that he or she will succeed in $\varphi$-ing. So, A merely has a degree of intention to $\varphi$. For instance, in Tourism, Michelle is highly confident but not certain that she will succeed in visiting Cathedral ${ }_{\mathrm{i}}$. Accordingly, she has a high degree of intention to visit Cathedral ${ }_{\mathrm{i}}{ }^{20}$

Suppose that a growing number of philosophers start thinking that intentions come in degrees. Then, for the rationality theorist, the next questions will be: Which structural requirements govern these attitudes? For instance, should there be structural requirements governing the strength of various intentions ${ }^{21}$ Should we abandon the structural requirements expressed in terms of full intentions and replace them with requirements for degrees of intention? Should there be a 'Lockean' thesis for translating rational degrees of intention into rational full intentions ${ }^{22}$ The point here is that, as accounts of attitudes evolve, new structural requirements could appear or replace other putative structural requirements. So, not only is the list of putative structural requirements already very long, but it could evolve over time. This is a problem for the Requirement-Based Approach.

\subsection{The Property-Based Approach}

Given these worries, many philosophers turn to the Property-Based Approach - that is, they work from a distinctive feature, or property, underlying all the putative structural requirements.

19 According to cognitivists about intentions, necessarily, if A intends to $\varphi$, A believes that one will $\varphi$. See notably Harman (1986, chap. 8), Setiya (2007) and Velleman (1989, chap. 4) on cognitivism about intentions. See Bratman (2009), Brunero (2009), Kiesewetter (2017, 277-80), and Wallace (2001) for criticism of cognitivism about intentions.

20 Note that the claim that beliefs (and intentions) come in degrees is compatible with 'full' notions of belief and intention. For example, in a 'Lockean' perspective, we can assume that full beliefs (and intentions) simply refer to sufficiently high degrees of beliefs (and intentions). See Goldstein (2016, 6-7).

21 Depending on what the strength of intention tracks. Goldstein (2016) argues that the strength of intention tracks degrees of belief concerning the success of the action. Sharadin and Dellsén (2017) argue that the strength of intention tracks the strength of practical reasons favouring the action.

22 See note 20. 
The distinctive feature underlying the structural requirements is some sort of 'common denominator.' All structural requirements have the distinctive feature. But not all common denominators will allow us to distinguish structural requirements from other requirements or sources of normativity. For instance, structural requirements govern attitudes. But substantive requirements also govern attitudes. So, the fact that structural requirements govern attitudes is not their distinctive feature.

Finding the distinctive feature underlying all putative structural requirements is not a simple task. Historically, these requirements come from various traditions that are not cohesive with each other. $^{23}$ Once we realize how diverse the putative structural requirements are, we can seriously doubt that there is a distinctive feature underlying all of them. For instance, the following requirements are very different from each other:

Practical Enkrasia. Rationality requires that, if A believes that she ought to $\phi$, then A intends to $\phi$.

Transitivity of Preferences. Rationality requires that, if A prefers $\alpha$ to $\beta$, and A prefers $\beta$ to $\gamma$, then A prefers $\alpha$ to $\gamma$.

Non-Contradiction. Rationality prohibits believing (P\& P).

Conjunction Rule (for credences). Rationality requires that, if A assigns a credence of $X$ in $\mathrm{P}$, then $\mathrm{A}$ does not assign a credence of $\mathrm{Y}$ in $(\mathrm{P} \& \mathrm{Q})$ such that $\mathrm{Y}>\mathrm{X}$.

This is just a sample. As briefly discussed in the previous subsection, there are at least 25 putative structural requirements discussed in print.

The most discussed property-based analysis of structural rationality is this: structural rationality is coherence. ${ }^{24}$ But what is coherence, exactly? Or, more precisely: What do structuralists about rationality mean by coherence?

Some objectors think that I raise an illegitimate question. For them, 'coherence' just means 'structural rationality.' They cannot be wrong in thinking that structural rationality is coherence. Let me be clear: We can use the expression 'coherent' as a synonym of 'structurally rational.' However, if we take the Property-Based Approach seriously, we expect a more informative account of coherence. If all we have to say about coherence is that it means 'structurally rational,' this concept will not be helpful for figuring out the distinctive feature underlying all structural requirements. ${ }^{25}$

23 For instance, requirements of probabilistic coherence come from Bayesian epistemology, preference transitivity comes from decision theory, and enkratic requirements come from Aristotelian ethics.

24 See note 1.

25 I thank referees for inviting me to clarify this point. 
So, how can we substantiate what coherence means in the Why-Be-Rational? Debate? First, we can explore the genealogy of this debate: We can turn to papers in which the Why-Be-Rational? debate started, and perhaps they will tell us what coherence means in this specific debate. Second, we can turn to other fields that have theorized norms of coherence. Third, we can turn to regimented accounts of coherence that are meant to (or have the potential to) unify the structural requirements of rationality. In the next sections, I will explore each of these possibilities.

\section{Genealogy}

In the debates on structural rationality, we want to know what 'coherence' means. A first possibility is to turn to the genealogy of these debates. Perhaps all we need to do is go back to the papers in which the Why-Be-Rational? debates originated, and we will know what coherence means in these debates.

As I indicated in section 1.1, these debates originated in a series of papers by Niko Kolodny. In “Why Be Rational?” (2005), Kolodny says that 'it is relatively clear how we might settle questions about what rationality requires; it is whatever is necessary for coherence’ (Kolodny 2005, 511). So, maybe we will find our answer there.

However, in “Why Be Rational?” (2005), Kolodny doesn't tell us what he means by coherence, and he doesn't refer to authors who define rationality in terms of coherence. Later in the paper, he briefly mentions that Scanlon (1998, §1.4; 2007) and Davidson (1985) might endorse the picture of rationality as coherence he has in mind (Kolodny 2005, 559). However, a definition of coherence can't be found in these contributions. Section 1.4 of Scanlon's What We Owe to Each Other does not refer to coherence, and "Structural Irrationality" mentions coherence once, in a footnote, without defining what this concept means (Scanlon 2007, 92n12). In “Incoherence and Irrationality," Davidson refers to coherence once, but he does not define what this concept means, and he does not refer the reader to other papers (Davidson 1985, 346). However, Davidson often refers to consistency and says that it governs combinations of intentional states (ibid., 348). That's a start (but not a very informative one).

In later papers, Kolodny (2007; 2008a; 2008b) starts his introductions with brief

remarks on the relationship between rationality and coherence, without defining clearly 
what coherence means. ${ }^{26}$ He then refers the reader to four papers, by Broome (1999; 2005), Wallace (2001), and Scanlon (2007). Can we find out what coherence means in these papers? Broome’s “Normative Requirements” (1999) does not refer to coherence. In “Does Rationality Give Us Reasons?” (2005), Broome says that 'requirements of rationality... require various sorts of coherence among mental states' (Broome 2005, 330), but he doesn’t tell us what coherence means exactly, and he doesn’t refer the reader to other papers. As I have said in the above paragraph, Scanlon's “Structural Irrationality” doesn't define coherence. Finally, the last sections of Wallace's (2001) paper talk about coherence, but without defining what this concept means or referring to other papers.

Thus, early contributions to the Why-Be-Rational? debate won't help us figure out what coherence is supposed to mean.

You might think that Kolodny did not need to provide a definition of coherence. Perhaps what he means by coherence is simply 'structurally rational.' That is, coherence is not this independent property in terms of which structural rationality is being theorized. As I said in section 1.3, there is no problem with thinking that 'coherent' is a synonym of 'structurally rational.' But for present purposes, this way of thinking about coherence is unhelpful. Recall that, in accordance with the Property-Based Approach, we are trying to figure out the distinctive feature underlying structural requirements. If 'coherent' merely means 'structurally rational,' then of course it cannot be false that coherence is a feature of structural requirements. But this is not helpful for figuring out the distinctive feature of structural rationality.

\section{Other Fields}

Perhaps we can find what we are looking for in other fields. After all, norms of coherence have been theorized in various fields, like ethics and epistemology. ${ }^{27}$ Perhaps we just need to look there, and we will find the account of coherence we are looking for.

Here, my remarks are tentative. There are a lot of accounts of coherence in different fields. It is possible that there is one account somewhere that matches what structuralists

26 However, these papers give us some clues concerning what he means by formal coherence. For instance, he says that 'there is no attitude that one must have, or lack, to be formally coherent' (Kolodny 2007, 230).

27 One might also think that the theories of coherence found in decision theory could be relevant here. However, I address this account of coherence in section 4.1. This is the 'Sure-Losses' account of coherence, which prohibits dominated attitudes, vulnerability to Money-Pumping or Dutch Books, etc. 
have in mind. I can only begin to explore whether structuralists will find what they are looking for in other fields.

A first possibility is that the notion of coherence in the Why-Be-Rational? debate is directly inherited from another field. If this were the case, then we would probably be able to see this with a citation graph. So, I have classified various articles, monographs, and book chapters that define coherence in decision theory, ethics, epistemology, philosophy of law, and political philosophy. I have also classified various important contributions to the Why-Be-Rational? debate. I took the contributions that are cited more than 50 times in these fields and made a citation graph. ${ }^{28}$ Here is what I got:

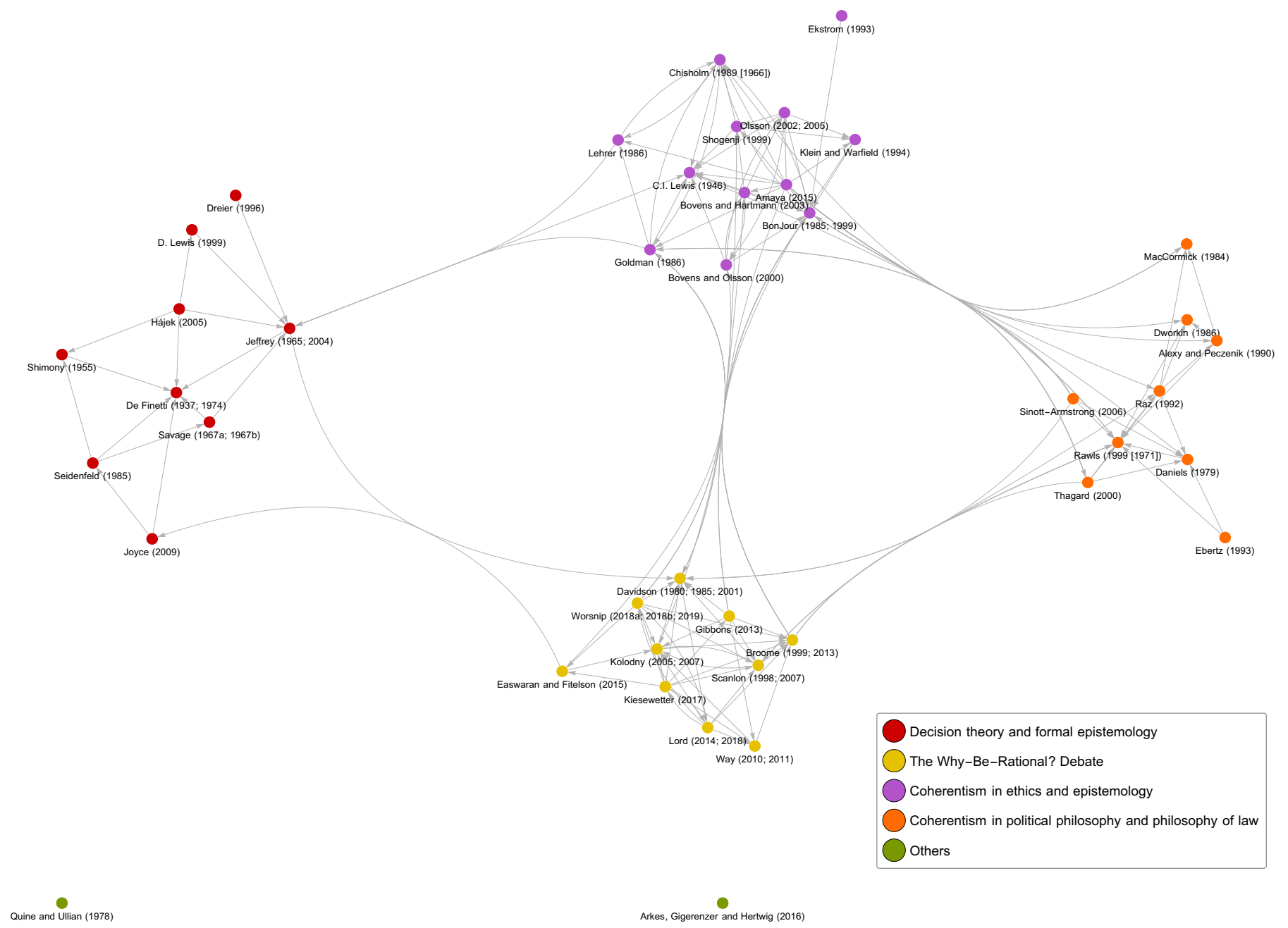

28 As of June 2020. I used the CommunityGraphPlot command in Mathematica. 
As we can see, this graph has four important citations clusters. Contributions to the Why-Be-Rational? debate form one of these clusters (the yellow one), and it is fairly isolated from the other ones. This suggests that authors engaged in this debate are not having a discussion with authors who have theorized coherence in other fields (or if they are, this is left implicit). Accordingly, it is hard to conclude that the notion of coherence discussed in the Why-Be-Rational? debate is directly inherited from another field (or that it mirrors a notion of coherence found in another field). This is not impossible, but this would be surprising.

Perhaps my citation graph is misleading. There could still be an account of coherence in other fields, like ethics or epistemology, that tracks what structuralists have in mind. However, the common accounts of coherence found in other fields, like ethics and epistemology, appear to be stronger than the notion structuralists have in mind.

If we were to infer an account of coherence from plausible structural requirements (like, e.g., Practical Enkrasia, Doxastic Enkrasia, Modus Ponens Rationality, and the Instrumental Principle), it would have the following features: First, there would be a bipartite taxonomy of coherence (i.e., non-coherent states are incoherent, and nonincoherent states are coherent). ${ }^{29}$ Second, coherence would be a proscriptive norm (that is, a norm that merely prohibits some combinations of attitudes). Third, mutual support among our attitudes would not be needed for coherence. In short: The account of coherence we are looking for is fairly weak. ${ }^{30}$

However, generally speaking, coherence is not understood like this in ethics and epistemology. Epistemologists and ethicists who have theorized norms of coherence see it as a criterion of mutual support among attitudes. For instance, Thagard says that 'a hypothesis coheres with what it explains, which can either be evidence or another hypothesis' (Thagard 2000, 43). Bovens and Olsson say that 'what coherentists do agree on is that a coherent information set is an information set whose members provide mutual support to each other' (Bovens and Olsson 2000, 688). Ekstrom says that 'cohering elements fit together; they hold together firmly, displaying consistency and mutual support'

29 The distinction comes from Audi $(2015,154)$. This claim is, of course, limited to agents. A rock can be neither coherent nor incoherent.

30 Broome (1999; 2013, sect. 7.3). See Fogal (2020) for discussion. 
(Ekstrom 1993, 608). For Sayre-McCord, 'to be coherent... each principle [of a moral theory] must either justify or be justified by other principles of the theory (the “connectedness requirement”)’ (Sayre-McCord 1985, 171). ${ }^{31}$ These accounts of coherence are way stronger than the requirements of structural rationality. Structural requirements promoting mutual support among attitudes are unheard of.

Think of a simple example. Consider the following three propositions: 'I have a cat,' 'John is Canadian,' and 'The President is in New York. ${ }^{\text {, }}$ These propositions do not support each other. Those who understand coherence in terms of mutual support will not think that these propositions are coherent with each other. At best, they are merely not incoherent. Now, suppose that Bob only has three attitudes. He believes the following propositions: 'I have a cat,' 'John is Canadian,' and 'The President is in New York.' Even if Bob’s beliefs do not support each other, they satisfy the putative structural requirements of rationality.

So, it is implausible that turning to other fields, like ethics or epistemology, will be helpful. Apparently, this is not where structuralists will find what they are looking for. Of course, this does not mean that structuralists about rationality cannot claim that structural rationality is coherence. But this means that the structuralist concept of coherence differs from the popular ones found in ethics and epistemology. ${ }^{33}$

\section{Sure-Losses and Dispositions}

Structuralists about rationality can offer regimented accounts of coherence that have the potential to unify putative structural requirements of rationality. There are two known suggestions for such accounts of coherence: the Sure-Losses account of coherence and Worsnip’s dispositionalist account of coherence. In this section, I analyze them.

31 Interpreting coherence as a norm of mutual support has deep historical roots-it goes back to authors like C. I. Lewis (1946, 338).

32 Similar examples can be found in BonJour $(1985,96)$ and Bovens and Hartmann $(2003,602)$.

33 As I said, my remarks in this section are tentative. There are other options on the table. If one looks at the citation graph, there are other clusters tracking work on coherence outside ethics and epistemology. The red one tracks the Sure-Losses accounts of coherence, but I will address this possibility in section 4.1. Perhaps the accounts of coherence found in political philosophy or philosophy of law could be helpful. But these accounts of coherence appear to be very far from what structuralists have in mind. 


\subsection{Sure-Losses}

Begin with the Sure-Losses account of coherence. This account finds its roots in decision theory and Bayesian epistemology. It roughly says that being incoherent is being vulnerable to exploitation or consists in having combinations of attitudes that are worse off than others in every possible world. ${ }^{34}$ And being coherent is avoiding these problematic states.

Dutch Book Arguments are probably the most common Sure-Losses arguments. Hájek summarizes Dutch Book Arguments as follows:

Dutch Books Arguments purport to show that there are rational constraints on [degrees of belief]... A Dutch Book is a series of bets bought or sold at such prices as to guarantee a net loss. An agent is susceptible to a Dutch Book... if there exists a series of bets bought or sold at such prices that she deems acceptable (by the light of her credences). (Hájek 2009, sect. 7.1)

But there are alternatives to Dutch Book Arguments. Some authors have used dominance principles to vindicate norms of consistency. For instance, for Joyce (1998), agents who violate requirements of probabilistic consistency are dominated, in the sense that their combinations of credences are less accurate (or less epistemically valuable) than other combinations of credences in every possible world. If rational agents care about the truth, they will not be satisfied with dominated combinations of credences. Dominance principles are now used for various vindications of Bayesian structural requirements. ${ }^{35}$

The Sure-Losses account of coherence has the merit of giving the beginning of an answer to the Why-Be-Rational? challenge. ${ }^{36}$ The fact that violating structural requirements entails some sort of vulnerability to exploitation, or dominated combinations of attitudes, seems like a good reason to satisfy them. Why should you satisfy the structural requirements of rationality? You should satisfy them because when you violate them, you become vulnerable to exploitation. Or when you violate them, you have attitudes that are more disvaluable than others in every possible world. This suggests that, when you violate structural requirements, you poorly manage your cognitive life. You should do better.

However, some plausible types of structural irrationality snake out of the SureLosses analysis. Take Modus Ponens Rationality. Agents can violate Modus Ponens

34 See, e.g., Davidson, McKinsey, and Suppes (1955), de Finetti (1937; 1974), Easwaran and Fitelson (2015), Joyce (1998), and Pettigrew (2016).

35 See Easwaran and Fitelson (2015) and Pettigrew (2016).

36 But of course, some questions and problems would remain, like the 'making space' problem. See Kolodny (2005) and Worsnip (2021). 
Rationality and avoid sure losses. For instance, suppose that P's evidential probability is high (but less than 1). Suppose also that the evidential probability that $\mathrm{P}$ entails $\mathrm{Q}$ is high (but less than 1). Then, an expected accuracy maximizer who avoids sure losses could believe $\mathrm{P}$ and believe that $\mathrm{P}$ entails $\mathrm{Q}$, but not believe $\mathrm{Q}$. This combination of attitudes might not be dominated. ${ }^{37}$ So, dominance reasoning doesn't seem to explain what is wrong with some putative structural requirements, like Modus Ponens Rationality.

Here is another example. Suppose that you violate Doxastic Enkrasia. Specifically, suppose you believe that you have sufficient evidence to believe that $\mathrm{P}$, but you decide not to believe P. Your attitudes violate a putative structural requirement. But are they dominated? That is, are there some combinations of attitudes that are better than the akratic ones in every possible world?

In order to answer this question, we first need to make some assumptions concerning epistemic value. Dominance reasoning is usually carried out in veritistic frameworks. In these frameworks, only true beliefs have final epistemic value and only false beliefs have final epistemic disvalue. ${ }^{38}$ Accordingly, $\mathrm{T}$ is the epistemic value of having a true belief (for $\mathrm{T}>0$ ), $\mathrm{F}$ is the epistemic disvalue of having a false belief (for $\mathrm{F}<0$ ), and the epistemic value of not believing $\mathrm{P}$ (or not disbelieving $\mathrm{P}$ ) is 0 .

Now, how do we argue that some attitudes are dominated? Some combinations of attitudes are dominated when there is a better alternative to them in every possible world. So, in order to determine whether akratic combinations of beliefs are dominated, we need to compare them with the other options agents have (in every possible world). The following table summarizes the options agents have, ${ }^{39}$ and the possible worlds they can be in:

37 These types of counterexamples are discussed in the literature on closure conditions. See, e.g., Easwaran and Fitelson (2015).

38 See, e.g., Pettigrew (2016).

39 I compare akratic beliefs with consistent combinations of attitudes. Inconsistent combinations of attitudes, such as believing P and disbelieving P simultaneously, are dominated (Joyce 1998; Pettigrew 2016). 
Table 1.

\begin{tabular}{||l||c|c||c||c||}
\hline $\begin{array}{c}\text { Doxastic options / } \\
\text { possible world }\end{array}$ & $\begin{array}{c}\text { P is true } \\
\text { and you } \\
\text { have SE for } \\
\text { believing P }\end{array}$ & $\begin{array}{c}\text { P is false } \\
\text { and you } \\
\text { have SE for } \\
\text { believing P }\end{array}$ & $\begin{array}{c}\text { P is true } \\
\text { and you } \\
\text { lack SE for } \\
\text { believing P }\end{array}$ & $\begin{array}{c}\text { P is false } \\
\text { and you } \\
\text { lack SE for } \\
\text { believing P }\end{array}$ \\
\hline $\begin{array}{l}\text { Akrasia: Believing you have } \\
\text { sufficient evidence (SE) for } \\
\text { believing P, but not believing P }\end{array}$ & $\mathrm{T}$ & $\mathrm{T}$ & $\mathrm{F}$ & $\mathrm{F}$ \\
\hline $\begin{array}{l}\text { Believing P and believing you } \\
\text { have sufficient evidence for } \\
\text { believing P }\end{array}$ & $2 \mathrm{~T}$ & $\mathrm{~T}+\mathrm{F}$ & $\mathrm{T}+\mathrm{F}$ & $2 \mathrm{~F}$ \\
\hline $\begin{array}{l}\text { Disbelieving P and believing you } \\
\text { have SE for believing P }\end{array}$ & $\mathrm{T}+\mathrm{F}$ & $2 \mathrm{~T}$ & $2 \mathrm{~F}$ & $\mathrm{~T}+\mathrm{F}$ \\
\hline $\begin{array}{l}\text { Believing P and not believing you } \\
\text { have SE for believing P }\end{array}$ & $\mathrm{T}$ & $\mathrm{F}$ & $\mathrm{T}$ & $\mathrm{F}$ \\
\hline $\begin{array}{l}\text { Neither believing P nor believing } \\
\text { you have SE for believing P }\end{array}$ & 0 & 0 & $\mathrm{~T}$ & $\mathrm{~T}$ \\
\hline $\begin{array}{l}\text { Disbelieving P and not believing } \\
\text { you have SE for believing P }\end{array}$ & $\mathrm{F}$ & $\mathrm{T}$ & $\mathrm{F}$ & $\mathrm{T}$ \\
\hline $\begin{array}{l}\text { Believing P and disbelieving you } \\
\text { have SE for believing P }\end{array}$ & $\mathrm{T}+\mathrm{F}$ & $2 \mathrm{~F}$ & $\mathrm{~T}$ \\
\hline $\begin{array}{l}\text { Not believing P and disbelieving } \\
\text { you have SE for believing P }\end{array}$ & $\mathrm{F}$ & $\mathrm{F}+\mathrm{F}$ & $\mathrm{T}$ \\
\hline $\begin{array}{l}\text { Disbelieving P and disbelieving } \\
\text { you have SE for believing P }\end{array}$ & $2 \mathrm{~F}$ & $\mathrm{~T}$ & \\
\hline \hline
\end{tabular}

In the above table, $\mathrm{T}$ denotes the value of having a true belief (for $\mathrm{T}>0$ ) and $\mathrm{F}$ denotes the disvalue of having a false belief (for $\mathrm{F}<0$ ). The columns represent the possible worlds one can be in. The rows represent the doxastic options one has. The first row represents a state of doxastic akrasia. When a cell has a red background, this means that, in this possible world, the option is epistemically worse than akratic beliefs. For instance, take the second row. If $\mathrm{P}$ is false and one has sufficient evidence for believing $\mathrm{P}$, then believing $\mathrm{P}$ and believing that one has sufficient evidence for believing $\mathrm{P}$ has lower epistemic value than akrasia. As we can see, we can't find an alternative to doxastic akrasia that is more valuable 
in every possible world (in each row, there is at least one red cell). This suggests that we can’t provide a dominance argument in favour of Doxastic Akrasia.

Now, dominance reasoning is just one type of sure-loss argument. There are also exploitation arguments that have to do with vulnerability to Dutch Books or Money Pumping, for example. What about these arguments? Hedden (2013) has argued that some agents who display some plausible types of structural irrationality are not subject to exploitation. He says that 'there are also cases where your credences are incoherent and yet there is no set of bets, each of which has a non-negative expected value, which together guarantee you a loss. Hence, you are provably invulnerable to Dutch Books. ${ }^{40}$ So, it seems that exploitation arguments do not cover all plausible cases of structural irrationality.

It should also be noted that there is no known argument showing that agents who violate the enkratic requirements or the Instrumental Principle (discussed in section 1.2) are vulnerable to exploitation. Yet it seems that being akratic or violating the Instrumental Principle is structurally irrational. Perhaps we will eventually find some explanations of why violating these requirements leads to exploitation, but it is currently unclear how we could do this.

So, it seems that the Sure-Losses account can't unify all the structural requirements discussed in print. To be clear: The Sure-Losses account of coherence can unify many putative requirements of structural rationality. There are anti-exploitation arguments for the transitivity of preferences, belief consistency, probabilistic requirements, and other requirements. ${ }^{41}$ The fact that many putative structural requirements can be explained in terms of avoiding dominance or exploitation is relevant. This can unify a subset of the putative structural requirements (more on this point in the conclusion). However, it is implausible that this is the distinctive feature of all structural requirements.

\subsection{Dispositions}

Worsnip’s dispositionalist account of coherence goes as follows: ${ }^{42}$

Coherence. 'A set of attitudinal mental states is jointly incoherent iff it is (partially) constitutive of the mental states in question that, for any agent that holds these attitudes,

40 Hedden $(2013,487)$.

41 See note 34.

42 There are similar accounts of coherence in print. See, e.g., Lee (2020). 
the agent is disposed, when conditions of full transparency are met, to give up at least one of the attitudes.' (Worsnip 2018a, 188)

As we can see, Worsnip's account of coherence is derivative of incoherence. Agents are coherent when they do not display incoherence. His account is proscriptive, as it merely prohibits some combinations of attitudes (i.e., the combinations of attitudes an agent is disposed not to have under conditions of full transparency).

There are three central concepts at play in Worsnip's account of coherencenamely, constitution, transparency, and dispositions. For Worsnip, a set of attitudes is incoherent if it is constitutive that, when some transparency conditions are satisfied, agents are disposed to give at least one of them up. Worsnip doesn't define what he means by 'constitutive.' Plausibly, he here means something like 'essential' (as opposed to 'derived from what makes us agents'). Then, there is full transparency. Here is how Worsnip defines transparency:

By 'conditions of full transparency,' I mean conditions under which the agent knows, and explicitly and consciously believes, that she has the states in question, without self-deception, mental fragmentation, or any failure of selfknowledge (pertaining to those attitudes). (Ibid.)

So, very roughly, the transparency condition is met when an agent's attitudes are known and salient to him or her. Note that the transparency condition can be met even if an agent does not acknowledge that his or her own combinations of attitudes are incoherent (ibid.). For instance, suppose Linda knows that she believes that P, and also that $\sim P$. Her beliefs can be transparent to her, even if she doesn't believe that 'believing $\mathrm{P}$ and $\sim \mathrm{P}$ simultaneously is incoherent' or that 'believing $\mathrm{P}$ and $\sim \mathrm{P}$ violates a requirement of rationality.' Finally, there are dispositions. When Worsnip says that incoherent agents are disposed to give up some of their attitudes, he means that they would find it hard to maintain them.

So, suppose Linda believes that $\mathrm{P}$ and believes that $\sim \mathrm{P}$ simultaneously. In order to determine whether she is (in)coherent, we need to ask ourselves: If Linda knew that she had such beliefs and wasn't in a state of self-deception, mental fragmentation or the like, would she be inclined to give up at least one of these beliefs? Would she find it hard to maintain these attitudes? Also, is her disposition to give up some of her beliefs an essential feature of 
her mental states? If the answer to these questions is 'yes,' then Linda is incoherent. If the answer to one of these questions is 'no,' then Linda is not incoherent.

One reason why Worsnip's account is interesting is that he is trying to find a notion of coherence that can unify structural requirements of rationality. For instance, he argues that his account can explain why instrumental irrationality, intransitive preferences, interlevel incoherent combinations of attitudes, and even akrasia are incoherent (Worsnip 2018a). So, Worsnip doesn't deny that there can be other legitimate notions of coherence in other fields. For him, we can be pluralist about what the concept of coherence means. However, he argues that there is a regimented, technical notion of coherence that reflects what structuralists about rationality have in mind.

In the remainder of this section, I'll argue that Worsnip's account faces a challenge. However, it is hard to find a clear counterexample to Worsnip's account, since he claims that, if a putative structural requirement $\mathrm{X}$ conflicts with his account, this might be a reason to deny that $\mathrm{X}$ is a genuine structural requirement (Worsnip 2018a, 187-8). But as Worsnip himself acknowledges, his account should not depart too much from what we typically take to be structural irrationality (ibid.).

So, I'll focus mostly on what philosophers have typically assumed to be structural irrationality. Specifically, I'll assume that violating some basic probability rules is structurally incoherent (as in, e.g., Broome $(2013,175)$ or Kolodny $(2007,229))$. At the end of the day, Worsnip could deny this assumption. But then, we will have learned something interesting. We will have learned that, all along, we were fairly mistaken concerning structural requirements of rationality. Or: Worsnip's account might unify some requirements of rationality, but these requirements are different from the ones structuralists about rationality have been concerned with over the past 15 years. This, I think, would not be a trivial observation.

\subsection{An Empirical Worry Concerning Probabilistic Consistency}

One problematic consequence of Worsnip's account of coherence is that the empirical literature on probabilistic inconsistency, which indicates that agents like us can easily 
violate basic probability rules, must also indicate that all of our incoherent combinations of attitudes are somehow not transparent to us. ${ }^{43}$ But this is implausible.

To see this, consider a well-known example: the Conjunction Rule, which says that $\mathrm{p}(\mathrm{A}) \geq \mathrm{p}(\mathrm{A} \& \mathrm{~B})$. In an empirical study, Tversky and Kahneman (1983) have argued that agents often violate the Conjunction Rule. ${ }^{44}$ Participants were presented with the following description of Linda, a fictional character:

Linda is 31 years old, single, outspoken and very bright. She majored in philosophy. As a student, she was deeply concerned with issues of discrimination and social justice, and also participated in anti-nuclear demonstrations. (Tversky and Kahneman 1983, 297)

Then, participants were asked to rank some propositions from 'most likely' to 'least likely,' including 'Linda is a bank teller' $(\mathrm{T})$ and 'Linda is a bank teller and is active in the feminist movement' (T\&F). When participants were asked to to indicate which possibility they think is more likely, they often indicated that $\mathrm{T}$ is less likely than $\mathrm{T} \& \mathrm{~F}$, which is probabilistically inconsistent.

Surely, if participants are asked to compare various propositions simultaneously, it might be less transparent to them that they are violating probability axioms. Since they process too much information simultaneously, they might not realize their mistake. In order to avoid this, a more 'transparent' version of the study was designed. Participants were explicitly 'compelled to compare the critical events' (ibid.). For instance, participants were asked only to rank T and T\&F. According to Tversky and Kahneman, these 'increasingly desperate manipulations [were] designed to induce subjects to obey the conjunction rule' (ibid., 299).

Plausibly, this version of the study satisfies Worsnip's transparency condition. Recall that, for Worsnip, our attitudes are transparent to us when we consciously know we have them, and when our minds are not fragmented or subject to other psychological obstacles. When participants are compelled to compare $\mathrm{T}$ and $\mathrm{T} \& \mathrm{~F}$ directly, it is maximally salient to them that they assign a higher rank (in terms of likelihood) to T\&F than to T. And while some participants could have faced some psychological obstacles during this version

43 There are other empirical studies suggesting that agents can be disposed to reason in a way that leads them to have incoherent attitudes. See, e.g., Arkes et al. (2016, 27-9) and Thorstad (2021) on adaptive rules that conflict with coherence requirements. Given our social, psychological, and biological goals, we use adaptive rules that that do not preclude incoherence.

44 This is an example among others. See the previous note. 
of the study (e.g., perhaps their own minds were opaque to them, or they did not have access to their own degrees of confidence during the study), it is implausible that all participants were in that situation. Yet the fact that participants were explicitly compelled to compare $\mathrm{T}$ and $\mathrm{T} \& \mathrm{~F}$ did not make a significant difference in the results. In fact, in every version of the study, more than $80 \%$ of participants violate the Conjunction Rule.

The best explanation of Tversky and Kahneman's observations is that we do not have an essential disposition to form attitudes coherently. Rather, we have other dispositions, and they can lead us to be incoherent. ${ }^{45}$ Accordingly, Worsnip's account faces a challenge. We do not necessarily have a disposition to be coherent.

Note, once again, that the transparency condition seems to be satisfied in some versions of these studies. Agents don't first assign a credence to T, and then, a couple of days later, after having forgotten their own credence in $\mathrm{T}$, assign a higher credence in $\mathrm{T} \& \mathrm{~F}$. Rather, agents claim, at the exact same moment, that $\mathrm{T}$ is less likely than T\&F. And they understand what 'likely' means. Some studies even include training in statistics and probability right before the participants are asked to rank various propositions. ${ }^{46}$ Even with training, a significant proportion of participants violate the Conjunction Rule. If Worsnip were right, we would have to conclude one of two things from these studies: either the participants are not incoherent or the participants did not satisfy the transparency condition. But both alternatives seem implausible.

One could argue that violations of the Conjunction Rule are not incoherent after all. Perhaps imperfect agents like us do not fall under an obligation to satisfy the probability axioms and thus can coherently violate some of them. ${ }^{47}$ However, we need to make a distinction between the following issues: (i) whether violating some requirements is permissible and (ii) whether violating some requirements is coherent (in the sense of

45 For Kahneman and Tversky, the best explanation of their observations is that our minds are designed to achieve representativeness (or correspondence). Very roughly, we are primarily disposed to believe and judge in accordance with assessments of correspondence between an outcome and a model. This is why, given Linda's background, we judge that 'Linda is a bank teller' $(T)$ is less likely than 'Linda is a bank teller and is active in the feminist movement' (T\&F). Given our disposition towards correspondence, we sometimes form judgments that conflict with coherence requirements.

46 Some later studies have suggested that there could be another explanation for why participants violate the Conjunction Rule. Specifically, it has been suggested that background knowledge of probabilities and statistical reasoning can also help participants achieve coherence. But even when they receive training in probability and statistics just before the study, a significant proportion of participants still violate the Conjunction Rule. See, e.g., Morier and Borgida (1984), Agnoli and Krantz (1989), and Epstein et al. (1999).

47 I thank a referee for inviting me to address this possibility. 
structurally rational). Even if we were sometimes permitted to violate the Conjunction Rule, this wouldn't mean that the Conjunction Rule is not a structural requirement of rationality. Many philosophers think that the probability axioms are central to structural rationality. For instance, Broome $(2013,175)$ thinks that some Bayesian requirements are requirements of rationality. Also, Kolodny (2007) says that there are '[rational] requirements of formal coherence... to have degrees of belief that satisfy the axioms of probability’ (Kolodny 2007, 229). Jeffrey $(2004,102)$ makes similar claims.

One could argue that violations of the Conjunction Rule are not instances of structural irrationality, but rather instances of substantive irrationality. Specifically, one could think that, for some propositions $\mathrm{P}_{1}$ and $\mathrm{P}_{2}$ and a body of evidence $\mathrm{E}$, the evidential probability of $\mathrm{P}_{1}$ conditional on $\mathrm{E}$ can't be less than the evidential probability of $\mathrm{P}_{1} \& \mathrm{P}_{2}$ conditional on E. So, when a thinker violates the Conjunction Rule, his or her attitudes are not responsive to the evidence. ${ }^{48}$

Three quick observations concerning this objection are in order: First, it should be noted that violations of the Conjunction Rule could be overdetermined. That is, violating the Conjunction Rule could be an instance of structural irrationality and an instance of substantive irrationality. There can be two different ways in which one is irrational. ${ }^{49}$ Second, there are 'unreasonable' ways to satisfy the Conjunction Rule. For instance, suppose that, relative to your evidence, $\mathrm{P}_{1}$ and $\mathrm{P}_{2}$ are uncertain propositions (these propositions could be either true or false). If you have a credence of 1 in $\mathrm{P}_{1}$ and a credence of 0 in $\mathrm{P}_{1} \& \mathrm{P}_{2}$, you satisfy the Conjunction Rule. Despite this, you fail to apportion your credences to your evidence. This suggests that the Conjunction Rule is a structural requirement, not a substantive one. When agents satisfy substantive requirements, they respond correctly to their reasons (or evidence). However, there are ways to satisfy the Conjunction Rule that are unresponsive to the evidence. Finally, it should be noted that the Conjunction Rule is just one example among others of a putative structural requirement that we often violate (Arkes et al. 2016, 27-9). Even if the Conjunction Rule were a substantive requirement, we could make the same point for other putative structural requirements.

As I said before, Worsnip could reject this counterexample. For instance, he could argue that basic consistency requirements (like the Conjunction Rule) are not part of 
structural rationality. But then, the lesson would be that, all along, philosophers working on

structural rationality were mistaken about this notion. Worsnip's account would be less a unification of putative structural requirements discussed over the past 15 years than a new account of these requirements.

\section{Conclusion and Discussion}

We have seen that, in the debates on structural rationality, the Requirement-Based Approach gives limited results. A better way to address these issues would be to identify a distinctive feature underlying all putative structural requirements. Call this the PropertyBased Approach.

A popular Property-Based Approach says that structural rationality is coherence. However, it is unclear how we should understand coherence. Papers in which the Why-BeRational? debate started are unclear about the meaning of coherence. In other fields, such as ethics and epistemology, coherence usually means something different (stronger) than what structuralists have in mind. And putative accounts of coherence that are meant to unify the structural requirements leave out some plausible structural requirements.

Given these problems, there are (at least) three good avenues for future research. A first, radical suggestion would be to give up on the distinction between structural and nonstructural (or substantive) rationality. Perhaps the distinction brings more confusion than clarity, and we should simply ask ourselves: What is rationality tout court, and do we fall under an obligation to be rational? But given that philosophers like Kolodny were merely concerned with a specific class of rational requirements (i.e., the so-called structural ones), this would amount to reframing the debate. However, if we really can't put our finger on what structural requirements consist in, this might be the best solution.

There are more conservative options on the table. Perhaps we should give up on the idea that structural rationality is a unified notion. Perhaps some 'structural' requirements stem from an immunity to sure losses, and other requirements have a different source. This 
would pave the way for a partial vindication of the normativity of structural rationality. For instance: Why do we fall under an obligation not to violate a class of structural requirements? It is because satisfying a class of structural requirements is a necessary condition for not being vulnerable to sure losses.

Finally, we can keep trying to find the putative distinctive features underlying all structural requirements. One possibility could be that structural rationality promotes good reasoning. ${ }^{50}$ We could also draw inspiration from Morgenstern and von Neumann (1953, 32), and define structural requirements as the necessary conditions of optimal decisionmaking in every possible scenario. These are just examples. There could be other possibilities. However, given that structural requirements come from various traditions and are quite different from each other, this approach strikes me as too ambitious. ${ }^{51}$

\section{References}

Agnoli, F., and D. H. Krantz. (1989). 'Suppressing Natural Heuristics by Formal Instruction: The Case of the Conjunction Fallacy.’ Cognitive Psychology 21(4): 515-550

Archer, A. (2017). 'Do We Need Partial Intentions?’ Philosophia 45(3): 995-1005

Arkes, H. R., G. Gigerenzer, and R. Hertwig. (2016). 'How Bad Is Incoherence?’ Decision 3(1): 20-39

Audi, R. (2015). Rational Belief: Structure, Grounds, and Intellectual Virtue. Oxford: Oxford University Press

BonJour, L. (1985). The Structure of Empirical Knowledge. Cambridge (MA): Harvard University Press

BonJour, L. (1999). ‘The Dialectic of Foundationalism and Coherentism.' In The Blackwell Guide to Epistemology, edited by J. Greco and E. Sosa, 117-142. Oxford: Blackwell

Bovens, L., and S. Hartmann. (2003). 'Solving the Riddle of Coherence.' Mind 112(448): 601-633

Bovens, L., and E. J. Olsson. (2000). 'Coherentism, Reliability and Bayesian Networks.' Mind 109(436): 685-719

Bratman, M. (2009). 'Intention Rationality.’ Philosophical Explorations 12(3): 227-241

Broome, J. (1999). 'Normative Requirements.’ Ratio 12(4): 398-419

50 See Dietrich et al. (2019) for a discussion.

51 Acknowledgments: Thanks to Bruno Guindon, Xander Selene, David Thorstad, and two anonymous referees for helpful comments. This research was supported by the Fonds de recherche du Québec Société et culture (grant \#268137) and the Social Sciences and Humanities Research Council (grant \#7562019-0133). 
Broome, J. (2005). 'Does Rationality Give Us Reasons?’ Philosophical Issues 15(1): 321337

Broome, J. (2013). Rationality through Reasoning. Oxford: Wiley-Blackwell

Brunero, J. (2009). 'Against Cognitivism about Practical Rationality.' Philosophical Studies 146(3): 311

Chislenko, E. (2016). 'Moore's Paradox and Akratic Belief.' Philosophy and Phenomenological Research 92(3): 669-690

Conee, E. (2010). 'Rational Disagreement Defended.' In Disagreement, edited by T. Warfield and R. Feldman, 69-90. Oxford: Oxford University Press

Daoust, M-K. (2019). 'Epistemic Akrasia and Epistemic Reasons.’ Episteme 16(3): 282-302

Daoust, M-K. (2020). 'The Explanatory Role of Consistency Requirements.' Synthese 197(10): 4551-4569

Daoust, M-K. (2021). 'Should Agents Be Immodest?’ Analytic Philosophy 62(3): 235-251

Davidson, D. (1980). Essays on Actions and Events. Oxford: Clarendon Press

Davidson, D. (1985). 'Incoherence and Irrationality.’ Dialectica 39(4): 345-354

Davidson, D. (2001). 'A Coherence Theory of Truth and Knowledge.' In Subjective, Intersubjective, Objective. Oxford: Oxford University Press

Davidson, D., J. C. C. McKinsey, and P. Suppes. (1955). 'Outlines of a Formal Theory of Value, I.’ Philosophy of Science 22(2): 140-160

De Finetti, B. (1937). 'La Prévision: Ses Lois Logiques, Ses Sources Subjectives.' Annales de l'institut Henri Poincaré 7: 1-68

De Finetti, B. (1974). Theory of Probability. Oxford: Wiley-Blackwell

Dellsén, F., and N. Sharadin. (2017). 'The Beliefs and Intentions of Buridan’s Ass.' Journal of the American Philosophical Association 3(2): 209-226

Dietrich, F., A. Staras, and R. Sugden. (2019). 'A Broomean Model of Rationality and Reasoning.' The Journal of Philosophy 116(11): 585-614

Dogramaci, S.. (2018). 'Solving the Problem of Logical Omniscience.' Philosophical Issues 28(1): 107-128

Douven, I., and W. Meijs. (2007). 'Measuring Coherence.' Synthese 156(3): 405-425

Easwaran, K. (2011). 'Bayesianism II: Applications and Criticisms.' Philosophy Compass 6(5): 321-332

Easwaran, K., and B. Fitelson. (2015). 'Accuracy, Coherence, and Evidence.' Oxford Studies in Epistemology 5: 61-96

Ekstrom, L. W. (1993). 'A Coherence Theory of Autonomy.' Philosophy and Phenomenological Research 53(3): 599-616

Elga, A. (2010). 'How to Disagree about How to Disagree.' In Disagreement, edited by T. Warfield and R. Feldman, 175-186. Oxford: Oxford University Press 
Elga, A. (2013). 'The Puzzle of the Unmarked Clock and the New Rational Reflection Principle.’ Philosophical Studies 164(1): 127-39

Feldman, R. (2005). 'Respecting the Evidence.’ Philosophical Perspectives 19(1): 95-119

Fogal, D. (2020). 'Rational Requirements and the Primacy of Pressure.' Mind 129(516): 1033-1070

Gibbons, J. (2013). The Norm of Belief. Oxford: Oxford University Press

Goldstein, S. (2016). 'A Preface Paradox for Intention.' Philosophers' Imprint 16(14). http://hdl.handle.net/2027/spo.3521354.0016.014

Greaves, H., and D. Wallace. (2006). 'Justifying Conditionalization: Conditionalization Maximizes Expected Epistemic Utility.’ Mind 115(459): 607-632

Hájek, A. (2009). 'Dutch Book Arguments.' In The Handbook of Rational and Social Choice, edited by P. Anand, P. Pattanaik, and C. Puppe, 173-195. Oxford: Oxford University Press

Harman, G. (1986). Change in View. Cambridge (MA): MIT Press

Hedden, B. (2013). 'Incoherence without Exploitability.’ Noûs 47(3): 482-495

Holton, R. (2008). 'Partial Belief, Partial Intention.’ Mind 117(465): 27-58

Horowitz, S. (2014). 'Epistemic Akrasia.’ Noûs 48(4): 718-744

Huemer, M. (2007). 'Moore's Paradox and the Norm of Belief.' In Themes from GE Moore, edited by S. Nucceteli and G. Seays, 142-157. New York (NY): Oxford University Press

Huemer, M. (2013). 'Phenomenal Conservatism.' In Internet Encyclopedia of Philosophy. https://www.iep.utm.edu/phen-con/

Jeffrey, R. (2004). Subjective probability: The Real Thing. Cambridge: Cambridge University Press

Joyce, J. (1998). ‘A Nonpragmatic Vindication of Probabilism.' Philosophy of Science 65(4): 575-603

Joyce, J. (2009). 'Accuracy and Coherence: Prospects for an Alethic Epistemology of Partial Belief.' In Degrees of Belief, edited by F. Huber and C. Schmidt-Petri, 263-297. Dordrecht: Springer

Kiesewetter, B. (2017). The Normativity of Rationality. Oxford: Oxford University Press

Kolodny, N. (2005). ‘Why Be Rational?’ Mind 114(455): 509-563

Kolodny, N. (2007). 'How Does Coherence Matter?' Proceedings of the Aristotelian Society 107(1.3): 229-263

Kolodny, N. (2008a). 'The Myth of Practical Consistency.' European Journal of Philosophy 16(3): 366-402

Kolodny, N. (2008b). 'Why Be Disposed to Be Coherent?' Ethics 118(3): 437-463

Lasonen-Aarnio, M. (2015). 'New Rational Reflection and Internalism about Rationality.' Oxford Studies in Epistemology 5: 145-171 
Lasonen-Aarnio, M. (2020). 'Enkrasia or Evidentialism? Learning to Love Mismatch.' Philosophical Studies 177(3): 597-632.

Lee, W. (2020). 'The Real Myth of Coherence.' Erkenntnis. DOI: 10.1007/s10670-02000239-y

Leitgeb, H., and R. Pettigrew. (2010a). 'An Objective Justification of Bayesianism I: Measuring Inaccuracy*.’ Philosophy of Science 77(2): 201-235

Leitgeb, H., and R. Pettigrew. (2010b). 'An Objective Justification of Bayesianism II: The Consequences of Minimizing Inaccuracy*.' Philosophy of Science 77(2): 236-272

Lewis, C. I. (1946). An Analysis of Knowledge and Valuation. LaSalle (Ill): Open Court

Lewis, D. (1971). 'Immodest Inductive Methods.’ Philosophy of Science 38(1): 54-63

Lord, E. (2014). 'The Coherent and the Rational.' Analytic Philosophy 55(2): 151-175

Lord, E. (2018). The Importance of Being Rational. Oxford: Oxford University Press

Meacham, C. J. G. (2015). 'Understanding Conditionalization.' Canadian Journal of Philosophy 45(5-6): 767-797

Mildenberger, C. D. (2019). 'A Reason to Be Rational.’ Inquiry 62(9-10): 1008-1032

Morgenstern, O., and J. Von Neumann. (1953). Theory of Games and Economic Behavior. Princeton (NJ): Princeton University Press

Nozick, R. (1993). The Nature of Rationality. Princeton (NJ): Princeton University Press

Pettigrew, R. (2016). Accuracy and the Laws of Credence. Oxford: Oxford University Press

Raz, J. (1992). 'The Relevance of Coherence.' Boston University Law Review 72: 273-321

Reisner, A. (2013). 'Is the Enkratic Principle a Requirement of Rationality?.' Organon F 20(4): 437-463

Sayre-McCord, G. (1985). 'Coherence and Models for Moral Theorizing.' Pacific Philosophical Quarterly 66(1-2): 170-190

Scanlon, T. (1998). What We Owe to Each Other. Cambridge (MA): Harvard University Press

Scanlon, T. (2007). 'Structural Irrationality.' In Common Minds: Themes from the Philosophy of Philip Pettit, 84-103. Oxford: Oxford University Press

Schoenfield, M. (2017). 'Conditionalization Does Not (in General) Maximize Expected Accuracy.’ Mind 126(504): 1155-1187

Setiya, K. (2007). 'Cognitivism about Instrumental Reason.’ Ethics 117(4): 649-673

Smithies, D. (2012). 'Moore's Paradox and the Accessibility of Justification.' Philosophy and Phenomenological Research 85(2): 273-300

Smithies, D. (2016). 'Belief and Self-Knowledge: Lessons From Moore's Paradox.' Philosophical Issues 26(1): 393-421

Thagard, P. (2002). Coherence in Thought and Action. Cambridge (MA): MIT Press 
Thorstad, D. (2021). 'The Accuracy-Coherence Tradeoff in Cognition.' British Journal for the Philosophy of science. DOI: 10.1086/716518

Titelbaum, M. (2015). 'Rationality’s Fixed Point (or: In Defense of Right Reason).' Oxford Studies in Epistemology 5: 253-294

Tversky, A., and D. Kahneman. (1983). 'Extensional versus Intuitive Reasoning: The Conjunction Fallacy in Probability Judgment.’ Psychological Review 90(4): 293-315

Velleman, D. (1989). Practical Reflection. Princeton (NJ): Princeton University Press

Wallace, J. (2001). 'Normativity, Commitment, and Instrumental Reason.' Philosophers' Imprint 1(4). http://hdl.handle.net/2027/spo.3521354.0001.004

Way, J. (2010). 'The Normativity of Rationality.' Philosophy Compass 5(12): 1057-1068

Way, J. (2011). 'The Symmetry of Rational Requirements.' Philosophical Studies 155(2): 227-239

Wedgwood, R. (2017). The Value of Rationality. Oxford: Oxford University Press

Worsnip, A. (2018a). 'What Is (In)Coherence?' Oxford Studies in Metaethics 13: 184-20

Worsnip, A. (2018b). 'The Conflict of Evidence and Coherence.' Philosophy and Phenomenological Research 46(1): 3-44

Worsnip, A. (2019). 'Disagreement as Interpersonal Incoherence.' Res Philosophica 96(2): 245-268

Worsnip, A. (2021). 'Making Space for the Normativity of Coherence’' Noûs, 1-23. DOI: 10.1111/nous.12362 